\title{
EDUCAÇÃO DO CAMPO E AS RELAÇÕES ÉTNICO-RACIAIS: olhares para o campesinato negro
}

\section{FIELD EDUCATION AND ETHNIC-RACIAL RELATIONS: looks at the black peasantry}

\author{
Magno Nunes Farias \\ Doutorando do Programa de Pós-Graduação em Educação na Universidade Federal de São Carlos - \\ UFSCar. Pesquisador do Núcleo de Extensão e Pesquisa em Educação e Desenvolvimento do Campo - \\ NEPCampo/UFCat. \\ magnonfarias@hotmail.com \\ Wender Faleiro \\ Professor do Programa de Pós-Graduação em Educação e da Licenciatura em Educação do Campo da \\ Universidade Federal de Catalão- UFCat. Pesquisador do Núcleo de Extensão e Pesquisa em Educação e \\ Desenvolvimento do Campo - NEPCampo/UFCat. \\ wender.faleiro@gmail.com
}

\section{Resumo}

O presente texto visa discutir as relações étnico-raciais na Educação do Campo (EC), voltando o olhar para o campesinato negro. A EC surge a partir dos movimentos sociais do campo, que buscam consolidar uma movimentação sociopolítica e cultural pela luta por uma educação que seja DO campo. Dentro dessa luta está o campesinato negro. Assim, a partir de levantamento bibliográfico e análise documental buscou-se realizar reflexões sobre a importância da EC pautar as relações étnico-raciais. Nota-se uma carência de produções que relacionam a EC e a importância de se tratar as relações étnicoraciais. A EC deve olhar de maneira mais intensa para relações étnico-raciais, pois existe um campesinato negro que deve ser pautado de maneira mais específica, sobre seus processos históricos e culturais não só como camponeses, mas como sujeitos negros. Pontua-se que as estruturas de opressões não são somente econômicas e sociais, mas de desigualdades étnico-raciais, e que educação de modo geral, deve superar qualquer reprodução de desigualdade. Assim, tratar as questões das relações étnico-raciais é fundamental para consolidar uma EC potente para realizar movimentos contrahegemônicos nas relações de desigualdade, e para consolidar uma Educação Libertadora.

Palavras-chave: Educação do Campo. Relações étnico-raciais. Campesinato Negro.

\begin{abstract}
The present text aims to discuss the ethnic-racial relations in the Field Education (EC), turning the look to the black peasantry. The EC arises from the social movements of the countryside, which seek to consolidate a socio-political and cultural movement for the struggle for an education that is OF the field. Within this struggle is the black peasantry. Thus, from a bibliographical survey and documentary analysis, it was sought to make reflections on the importance of EC to guide ethnic-racial relations. There is a lack of productions that relate the CS and the importance of dealing with ethnic-racial relations.
\end{abstract}


The EC must look more closely at ethnic-racial relations, for there is a black peasantry, which must be more specifically modeled on its historical and cultural processes not only as peasants, but as black subjects. First, the structures of economic and social oppression do not pervade only class, but ethnic-racial inequalities; Second, education in general, must overcome any reproduction of inequality. Thus, addressing the issues of ethnicracial relations is fundamental to consolidate a powerful EC to carry out counterhegemonic movements in the relations of inequality, and to consolidate a Liberating Education.

Keywords: Field Education. Ethnic-racial relations. Black Peasantry.

\section{Introdução}

A Educação do Campo surge a partir dos movimentos sociais do campo brasileiro, constituída pela classe trabalhadora do campo, que busca consolidar uma movimentação sociopolítica e cultural por uma educação que seja DO campo e não PARA o campo (CALDART, 2012). Sua base tem como ponto central a luta pela democratização do conhecimento e da terra, e busca a desconstrução de processos de inferiorizarão epistemológica, cultural e social do viver e existir no campo. Assim, a Educação do Campo se constrói a partir de uma perspectiva decolonial, libertadora e conscientizadora ${ }^{1}$, almejando um projeto societário pautado na classe trabalhadora do campo, e também das cidades. "Na sua origem, o 'do’ da Educação do campo tem a ver com esse protagonismo: não é 'para' e nem mesmo 'com': é dos trabalhadores, educação do campo, dos camponeses, pedagogia do oprimido...” (CALDART, 2009, p.41, grifos da autora).

A Educação do Campo possui um processo histórico longo, apesar de ela ser colocada enquanto política pública e nomeada Educação do Campo recentemente, a partir da década de 1990. Podemos conceber que suas bases históricas estão estreitamente relacionadas com as experiências de educação dos Movimento dos Trabalhadores Rurais Sem Terra, que tem como base também a perspectiva da Educação Popular, que se constrói na busca de educação que dialogue diretamente com seus modos de vida, produção e cultura.

A especificidade da Educação do Campo, em relação a outros diálogos sobre educação deve-se ao fato de sua permanente associação com as questões do desenvolvimento e do território no qual ela se enraíza. A afirmação de que só há sentido no debate sobre Educação do Campo como parte de uma reflexão maior sobre a construção de um Projeto de Nação, popular e revolucionário, é o chão inicial capaz de garantir o consenso dos que se reúnem em torno desta bandeira (MOLINA, 2006, p.10). 
Assim, a Educação do Campo está entrelaçada pela construção de um campo pautada na justiça social e no protagonismo do povo, assim, ela se constrói nas questões que perpassam esse território, as potencializas, a cultura, os conflitos, a história, ou seja, nas pessoas que vivem e re(existem) nesse espaço. Para assim, realmente tem um projeto popular revolucionário, que contemple as necessidades dos sujeitos e seus modos de existências (MOLINA, 2006).

A Educação do Campo se caracteriza como um movimento em construção, que procura um paradigma teórico e político que superem concepções hegemônicas marginalizadoras, urbanocêntricas e etnocêntricas, ou seja, padrões de poder que inferiorizam o campo. Pautando-se e lutando por uma Educação do Campo onde os povos do campo sejam valorizados em suas diversas dimensões, como sujeitos com infinitas experiências e construção de conhecimento, cultura e alternativas de vida que devem ser valorizadas. Tendo o campo como espaço que está em pleno movimento epistemológico, ontológico e educativo (CALDART, 2008; 2009)

Dentre os povos que lutam pela Educação do Campo, está o campesinato negro, que compõem o campo brasileiro de forma heterogênea, nos quilombos, comunidades rurais negras, nos movimentos sociais do campo, são os trabalhadoras e trabalhadores do campo, assentamentos, ou seja, estão nos diversos espaços que marcam o território camponês brasileiro. Assim, estamos aqui nos referindo aos sujeitos negros do campo, que dentro desse espaço elaboram “[...] formas específicas de ser e existir enquanto camponês e negro" (GUSMÃO, 1990, p.26). Desta maneira, aqui falamos de sujeitos que estão se construindo e possuem suas vivências, historicidade, ancestralidade e cultura marcada pelas questões de ser camponês e ser negro, pois essa dupla identidade estrutura suas vidas cotidianas e suas relações com o mundo.

\section{Relações étnico-raciais e Educação}

Para compreender o que desenvolvemos enquanto relações étnico-raciais é essencial entender as dimensões de raça e etnia, que em primeiro momento já afirmamos que estamos focando nas relações do grupo étnico-racial negro. Assim, aqui vamos falar sobre as relações sociais que envolvem o Negro brasileiro, os processos de racismo, desigualdade racial, resistência e identidade negra que os envolvem, e a Educação enquanto possibilidade de transformação de relações étnico-raciais de opressão, na busca 
de uma educação decolonial, intercultural, antirracista, que empodere o povo negro brasileiro.

Assim, compreendemos aqui a raça como um ponto central, enquanto conceito político que demarca as relações de desigualdade historicamente construídas, reproduzidas e legitimadas nas relações interpessoais e pelas instituições sociais. Gomes (2002) aponta que o conceito de raça é entendido a partir de uma construção e perspectiva social, histórica e política, que vem sendo ressignificado pelo movimento Negro no Brasil, e que perpassa o entendimento da existência de uma diferença entre os sujeitos negros e não negros. Desta forma, o termo raça possui "um significado político construído a partir da análise do tipo de racismo que existe no contexto brasileiro e considerando as dimensões histórica e cultural que este nos remete" (GOMES, 2005, p.47). Assim, ao utilizar o termo raça não estamos o compreendendo enquanto distinção biológica, mas sim o seu significado político e ideológico, tendo em vista que a sociedade ainda se estrutura dentro de dinâmicas que colocam a raça como categoria de dominação e exclusão, pois não se pode negar que a raça tem operado na estrutura social, pautado em características físicas que diferem um corpo negro do branco, pois essa noção está incorporada nas representações e imaginários sociais e contribui para a reprodução de desigualdades (MUNANGA, 2009). Desta forma, o conceito de raça utilizado aqui diz respeito à compreensão de como a raça, enquanto categoria fundada sob um viés racista se tornou fundamental e foi ressignificada para compreender as relações entre negros e não negros na sociedade brasileira. Logo, a diferença racial se dá em uma perspectiva construída culturalmente, que demarca diferenças corporais e ancestrais entre as pessoas, e dentro da dinâmica social as caracteriza enquanto raça negra ou não negra. Assim, assumir a raça enquanto categoria histórico, social, cultural e política é fundamental para entendermos as relações entre negros e não negros, e para além, o movimento Negro tem assumido esse conceito para se afirmar e empoderar enquanto grupo que se constrói entre diversas opressões, mas tem orgulho de sua raça, de ser negro.

O outro termo essencial para essa discussão é de etnia, esse termo demarca os processos históricos e culturais que caracteriza o povo negro, diz respeito a um pertencimento ancestral e tradicional (MUNANGA e GOMES, 2016). Assim, demarcamos que sujeitos que compõem um grupo étnico são "uma agregação consciente de pessoas unidas ou proximamente relacionadas por experiências compartilhadas" 
(CASHMORE, 2000 p.196 apud GOMES, 2005). A partir do entendimento que esses dois termos contemplam e dialogam entre si, alguns autores optam por utilizar a expressão étnico-racial, que também é defendida por nós, entendendo que questões que envolvem o negro no Brasil se dá de forma complexa dentro de diversas dimensões, que envolve cultura, textura do cabelo, cor da pele, ancestralidade, linguagem, entre outras questões que demarcar sua historicidade e sua existência atual. Assim a expressão étnico-racial quando utilizada para

[...] nos referirmos ao segmento negro da população brasileira, tanto na dimensão cultural (linguagem, tradições, ancestralidade) quanto a racial (características físicas visivelmente observáveis, tais como cor de pele, tipo de cabelo etc.) são importantes e estão articuladas. Ambas dever ser consideradas em conjunto (e não de forma separada) quando falarmos sobre a complexidade do que representa "ser negro no Brasil" (GOMES e MUNANGA, 2016, p. 178).

Essas relações étnico-raciais são demarcadas por diversas formas de opressão e desigualdade, que possuem origem desde a colonização da África, e o sequestro do povo negro africano para terras brasileiras, a escravidão. Assim, "mediata exploração da nova terra se iniciou com o simultâneo aparecimento da raça negra fertilizando o solo brasileiro com suas lágrimas, seu sangue, seu suor e seu martírio na escravidão" (NASCIMENTO, 1978, p.48). Desta forma, esses processos de opressão, dominação e violência ainda "cortam" a existência do negro hoje a partir das diversas facetas do racismo e a desigualdade racial que marcam os contextos atuais, inclusive a educação.

Sendo assim, o racismo é característica que marca as relações étnico-raciais, e atinge a população negra brasileira, sendo ele um comportamento fundamentado nas características raciais e étnicas (cor de pele, cabelo, cultura, ancestralidade, entre outros). O racista crê na concepção que existem raças inferiores e superiores, um exemplo dessa postura foram as teorias elaboradas para legitimar a escravidão dos povos negros no século XIX, e todo processo de exclusão e discriminação racial que os sujeitos negros sofrem até os dias atuais. O racismo pode ocorrer em circunstâncias individuais (cometido por um indivíduo contra outro) e institucionais (serviços escolares, de saúde, etc., com apoio direito ou indireto do Estado), legitimando os preconceitos raciais e a prática da discriminação (MUNANGA e GOMES, 2016). Assim, o racismo marca a existência do povo negro no Brasil, e exige estratégias de luta e resistência histórica para esses sujeitos serem visto como humanos. 
Nesse processo, o racismo gera um abismo racial ou desigualdade racial, que são apontados, por exemplo, sobre diferença da escolaridade, do emprego e moradia entre sujeitos negros e brancos, e acaba comprovando a existência de uma desigualdade racial no processo de acesso ao sistema educacional, e que os negros ocupam postos de trabalho desqualificados e precarizados com piores remunerações, moram em território periféricos, ou seja, os negros possuem condições de vida mais precárias quando comparadas com a de sujeitos brancos (GONZALES e HASENBALG, 1982; MUNANGA e GOMES, 2016).

Além disso, as práticas do racismo realizam um processo de incorporação da inferioridade no sujeito negro, pois a construção do branco enquanto belo, inteligente, superior e ideal inviabiliza a construção do empoderamento e da Identidade Negra. Esses aspectos geram as dificuldades do negro em aceitar suas características físicas negras, sua cor, sua ancestralidade, sua cultura, sua história, sua beleza, sua potencialidade. Assim, o racismo individual e institucional faz com que o sujeito negro incorpore o complexo de inferioridade e a ausência de consciência política e histórica sobre si enquanto raça e etnia (MUNDANGA, 2009; FANON, 1969). O racismo despoja em múltiplas dimensões, sejam elas objetivas, que inviabilizam os acessos e a permanecia do negro em determinados lugares, sejam subjetivas que tendem a incorporar no negro o ideal de branquitude, sendo inferiorizada a sua negritude e a possibilidade de existir dentro dela.

"Diz-se correntemente que o racismo é uma chaga da humanidade. Mas é preciso que não nos contentemos com essa frase. É preciso procurar incansavelmente as repercussões do racismo em todos os níveis da sociabilidade” (FANON, 1969, p.40). Desta forma, o autor pontua que não basta atestarmos a existência perversa do racismo nas relações étnico-raciais, mas mapear, procurar, descobrir suas sutilezas na estruturação de uma sociedade racialmente desigual e, sobretudo, pontuarmos a necessidade de se pensar possibilidades, estratégias e caminhos para a sua superação, desconstrução, na busca do reconhecimento e valorização da raça/etnia negra, a partir da legitimação de sua história, cultura, traços corporais, expressões artísticas, lutas e resistências. Assim, a pergunta que colocamos aqui é: Dentro dessa estrutura e dinâmica social complexa, qual a importância de uma Educação que paute as relações étnico-raciais?

Nesse sentido Silva e Barbosa (1997) trazem a reflexão sobre a educação para as relações étnico-raciais e práticas antirracistas, pontuando a importância desse ser um 
espaço não somente de denúncia das opressões e desumanização dos sujeitos negros, mas também espaço para desenvolver um conhecimento crítico da realidade vivenciada por esses sujeitos e de suas necessidade sociais, os colocando como sujeitos protagonistas das ações, para que assim possa-se pensar em estratégias a partir de suas próprias ações e movimentos de resistência. Assim, uma educação que epistemologicamente e ontologicamente dê centralidade ao povo negro (na elaboração de seus pensamentos e práticas de luta, expressão cultural, formação humana, que tem raízes na África, e suas experiências de enfrentamento do racismo e desigualdade racial), para desenvolver uma educação étnico-racial para o empoderamento e na construção da identidade negra do povo negro e a para a reflexão do branco sobre o seu lugar na luta antirracista (superando práticas de racismo e imaginários de inferiorização do povo negro, e reconhecendo sua braquitude que possui privilégios, a fim de desconstruí-la). Entendendo assim, a busca por uma Educação pautada na interculturalidade crítica, para a "construção de e a partir das pessoas que sofreram uma histórica submissão e subalternização" (WALSH, 2009), superando uma educação eurocêntrica, voltada para as relações de colonialidade, abrindose formas historicamente marginalizadas de educar e viver, focando no movimento do povo Negro (MUNANGA, 2005; WALSH, 2009).

Uma Educação fundamentada nas perspectivas antirracista e de reconhecimento das práticas sociais do povo negro. Reconhecendo assim, o lugar do negro na construção material, cultural, ideológica para a transformação da sociedade brasileira, bem como superando uma historiografia pautada exclusivamente em afirmação do lugar do negro enquanto apenas escravo, mas mostrando suas ações enquanto sujeito de cultura, resistência, luta, conhecimento, estética (SILVA e BARBOSA, 1997). Essa prática educativa busca que os sujeitos negros e não negros “[...] rompam com sentimentos de inferioridade e superioridade, se desconsiderem julgamentos fundamentados em preconceitos, deixem de se aceitar posições hierárquicas forjadas em desigualdades raciais e sociais" (SILVA, 2007, p.490).

O texto de Silva (2001), intitulado Pode a educação prevenir contra o racismo e a intolerância? nos ajuda a refletir sobre a questão colocada incialmente. Dentro do seu percurso a autora coloca que a educação pode ou não pode, e para isso é necessário que a educação, em seu próprio contexto de produção (formal ou não-formal), seja capaz de superar lógicas de dominação discriminatórias e preconceituosas (baseadas na educação 
eurocêntrica/colonizadora/racistas), para a busca de solução e caminhos conjuntos aos sujeitos negros que produzem epistemologias e formas de vida com princípios educativos. Há a necessidade de construir estratégias educativas com base na vivência dos povos negros e na valorização dos mesmos, estendendo que esse processo diz respeito à sociedade negra e não negra, tendo como base a promoção do "conhecimento mútuo, e a condição de iguais direitos garantidos as diferenças" (SILVA, s/p, 2001), que busca alternativas ao eurocentrismo, voltando a interculturalidade crítica.

Essa construção está relacionada com a superação do mito da democracia racial que incorpora "a noção de que a nação brasileira oferece a todos os seus cidadãos, negros, pardos ou brancos, igualdade de oportunidades em todas as áreas da vida pública e um convívio harmonioso, livre do racismo e da discriminação racial" (ZUBARAN e SILVA, 2012, p.132). Pois, esse mito acaba contribuindo para a invisibilidade da questão racial no país, desta forma, a Educação antirracista deve colocar esse assunto em pauta, tendo em vista que a democracia racial não existe, discutindo os conflitos e desigualdade étnicoraciais, e buscando junto com os sujeitos negros caminhos para a uma prática antirracista e consciente na realidade vivida.

Assim, concordamos com Munanga (2005, p.17), pois acreditamos “[...] que a educação é capaz de oferecer tanto aos jovens [e crianças] como aos adultos a possibilidade de questionar e desconstruir os mitos de superioridade e inferioridade entre grupos humanos que foram introjetados pela cultura racista na qual foram socializados". Tendo em vista que o racismo se estrutura na sociedade, inclusive na educação, porém entendemos a educação também como uns dos lugares potentes para desconstrução dessa estrutura. A Lei 10.639/03 surge nessa perspectiva, ao decretar a obrigatoriedade da inclusão da História da África e Cultura Afro-Brasileira no currículo escolar das escolas públicas e particulares de educação básica. Assim, essa lei se introduz “[...] não como mais disciplinas e novos conteúdos, mas como uma mudança cultural e política no campo curricular e epistemológico - poderá romper com o silêncio e desvelar esse e outros rituais pedagógicos a favor da discriminação racial” (GOMES, 2012, p.105).

Desta forma, as perguntas que tentaremos colocar em debate são: Como a Educação do Campo vem tratando as questões que envolvem as relações étnico-raciais? Qual a importância da Educação do Campo olhar para as relações étnico-raciais para fortalecer o Campesinato Negro? É possível construir uma Educação do Campo 
libertadora para os sujeitos negros e não negros camponeses sem pautar os tencionamentos das relações étnico-raciais?

Vale pontuar que compreendemos a necessidade de a Educação do Campo debruçar-se nas relações étnico-raciais que diz respeito não somente a campesinato negro, mas o campesinato não-negro, tendo em vista que para construir uma Educação do Campo intercultural e liberadora é necessário articular todas essas formas de existir no campo. Porém, vamos centralizar nossa discussão nas relações étnico-raciais do povo negro, do campesinato negro, entendo a carência e a necessidade de dar centralidade a esses povos e suas necessidades nesse território.

Desta forma, o objetivo desse trabalho é refletir sobre a importância de se discutir as relações étnico-raciais na Educação do Campo, principalmente para fortalecer a identidade $^{2}$ do campesinato negro, mas também para fortalecer a educação libertadora para sujeitos negros e não-negros, pontuando a importância de se formar sujeitos capazes de superar qualquer forma de opressão e desigualdade racial e social.

\section{Metodologia}

A presente pesquisa é qualitativa, se classifica como trabalho de reflexão, onde se busca realizar diálogos sobre a importância de a Educação do Campo pautar as relações étnico-raciais. Para subsidiar esse percurso reflexivo-crítico realizou-se análise de documentos e revisões bibliográficas.

O mapeamento dos dados foi realizado em cinco, dos sete cadernos da Coleção "Por uma Educação do Campo", a saber: 1 - Por uma educação básica do campo (memória); 2 - A educação básica e o movimento social do campo, 67p; 3 - Projeto popular e escolas do campo, 63p; 4 - Educação do Campo: identidade e políticas públicas, 92p; 5 - Contribuições para a Construção de um projeto de Educação do Campo 75p; 6 Projeto Político-Pedagógico da Educação do Campo - $1^{\circ}$ Encontro do Pronera na região Sudeste; 7- Educação do Campo Campo - Políticas Públicas - Educação, 117p) só não foram avaliados o primeiro e o sexto devido ao não acesso aos mesmos.

As análises ocorreram a partir da busca nos documentos dos seguintes descritores: relações étnico-raciais; relações raciais; relações étnicas; raça; etnia; negro; negra; afrodescendente; racismo; étnico; racial; desigualdade racial. Além disso, realizamos uma pesquisa no bando de dados scielo e google acadêmico e no banco de Teses e 
Dissertações BDTD (Biblioteca Digital Brasileira de Teses e Dissertações), vinculando os descritores acima com o descritor Educação do Campo, no campo título da busca. Assim, com esses descritores busquemos mapear de maneira mais ampla possível questões que tivessem relacionadas com as relações étnico-raciais centradas na população negra.

\section{Resultados e discussões}

Para melhor organização dos resultados os separamos no sentido de refletir sobre cada questão colocada acima, haja vista, que essas estão constantemente relacionadas. Apesar de sinalizarmos perguntas, aqui não procuramos traçar respostas fixas, tendo em vista as limitações de espaço e a inexistência de respostas totalizantes, pelo contrário, buscamos tencionar as temáticas e contribuir para a construção de novos diálogos, críticas e reflexões.

\section{Como a Educação do Campo vem tratando as questões que envolvem as Relações étnico-raciais que envolvem o negro?}

Ao expor os fragmentos dos Cadernos não citaremos o autor da citação, entendo que nossa análise não se dá para expor ou criticar os textos ou percursos teóricos individualizando a questão para o autor, mas refletir sobre como as relações étnico-raciais são colocadas nos cadernos, tendo em vista que esses documentos narram a história da Educação do Campo, e atualmente são fontes essenciais que tem o potencial de conduzir sua construção teórico-prática no país.

No caderno 02 (ARROYO e FERNANDES, 1998) identificamos os descritores: raça (3) e negro (2). Assim, dentro desse caderno as palavras raça e negro aparecem nas seguintes situações:

\footnotetext{
"O movimento no campo não é só de homens. Todos, mulheres, homens, crianças, jovens integrados nesse movimento social, constituindo-se como sujeitos de direitos. Acordando e lutando. A escola reconhecendo a história concreta de cada educando, do coletivo, da diversidade dos gêneros, das raças, das idades..." (p.19/20).

"Não tratem o aluno como número, não tratem o aluno como aluno, tratem como sujeitos, sujeitos que trazem história, que têm diferenças. É diferente ser mulher e homem, negro e branco. É diferente ser criança, do que ser adolescente/jovem. Tratar o aluno como gente, no seu tempo, na sua idade, no seu gênero, na sua raça, na sua história, na sua diversidade, no seu momento de formação humana” (p.20)

"Uma coisa que me impressionou aqui é que nas suas músicas vocês falavam: sou criança, sou negro, sou índio, sou brasileiro, não é verdade?”
} 
Os autores dos trechos acima trazem a ideia e pontuam os Movimentos Sociais do Campo como espaços de produção pedagógica, que conseguem ultrapassar o modelo hegemônico de escola que olha os estudantes como objetos. Assim, a raça e o ser negro, são apontados por ele como questões que os Movimentos Sociais do Campo pensam ao realizar uma experiência educativa escolar, pois os autores afirmam que esses movimentos reivindicam essa identidade negra e racial em alguma proporção. Diz então da potência dos Movimentos Social do Campo em realizar uma educação do campo que reconheça as diferenças. Essas falas, apesar de serem colocadas sem aprofundamentos, afirmam a Educação do Campo e seus vínculos com movimentos sociais, ser espaço potente para a construção de lugares de educação que promovam novas relações sociais, pautada no antirracismo e não pertencimento étnico-racial (SILVA, 2001; SILVA, 2007).

No Caderno 03 (BENJAMIN e CALDART, 2000) as palavras achadas foram, racial (1) e raça (1), e em nossa perspectiva esses conceitos se inserem no texto de forma problemática. Os fragmentos são:

"Nenhum projeto nacional pode-se construir aqui, com autenticidade, tendo como base [...] ideias de superioridade de qualquer tipo, muito menos racial (pois nossa afirmação só pode basear-se no elogio da mistura) ".

"[...] nenhum grupo pode se definir como "puro", nem como "centro", nem como portador de uma lealdade étnica ou cultural extranacional. Todos foram assimilados e abrasileirados" (p.17).

"[...]A identidade dos brasileiros não pode ter como base uma vocação imperial, o preconceito, a segregação, a religião, a raça. Ela só pode ser construída no terreno da cultura (p.17)

Os autores desses fragmentos constroem um tópico dialogando sobre os princípios de um projeto popular para o Brasil, pontuando algumas necessidades para que consolidemos um projeto popular nacional, tendo em vista que essa perspectiva é colocada pela Educação do Campo para o desenvolvimento de um país pautado na justiça social. Assim, a concepção dos autores em pontuarem que não se deve na superioridade racial se coloca com algo fundamental, porém, acreditamos que é preciso aprofundamento e é necessário entender que as questões da raça e das desigualdades geradas por ela marcam o Brasil. Pois, basear-se no elogio a mistura não é suficiente para desconstruir essas desigualdades pautadas no racismo.

Outra questão que pontuamos como equivocada é que os autores afirmam que nenhum grupo pode se ver como portador de uma lealdade étnica ou pontuar a identidade brasileira não pode ter base na raça, tendo em vista que as marcas do corpo negro e o 
lugar do negro na sociedade brasileira são profundamente marcados por sua ancestralidade, culturalidade e historicidade (MUNANGA e GOMES, 2016). Assim, entendemos que a etnia é elemento central nas relações sociais e a identidade brasileira se constrói a partir dessas relações que permite os sujeitos a se identificar e pertencer a uma etnia. Nesse sentido Munanga pontua

\begin{abstract}
Se nossa sociedade é plural, étnica e culturalmente, desde os primórdios de sua invenção pela força colonial, só podemos construí-la democraticamente respeitando a diversidade do nosso povo, ou seja, as matrizes étnico-raciais que deram ao Brasil atual sua feição multicolor composta de índios, negros, orientais, brancos e mestiços (2005, p.17/18).
\end{abstract}

Desta maneira, o caminho para uma educação pautada no projeto popular para o Brasil não se dá na anulação dos pertencimentos étnicos de cada grupo, mas na democratização do respeito à diversidade das matrizes étnicas do país. Essas afirmações do caderno 03 podem sustentar o mito de democracia racial no Brasil, e isso é bastante perigoso, pois "o discurso da democracia racial contribuiu também para camuflar o racismo e encobrir as desigualdades e os conflitos étnico-raciais, dificultando a construção de identidades específicas e o poder de contestação dos excluídos" (ZUBARAN e SILVA, 2012, p.132). Tendo em vista que temos que reconhecer as diferenças étnico-raciais e lidar com elas, não anulando, mas superando perspectivas racista e preconceituosa (GOMES, 2005) para buscar uma Educação do Campo que afirma a diversidade étnico-racial na construção nacional. Pois o "ocultamento da diversidade étnico-racial brasileira impediu que a comunidade afro-brasileira tivesse acesso às suas memórias, à sua história e ao seu patrimônio" (ZUBARAN e SILVA, 2012, p.133).

No Caderno 04 (KOLLING, CERIOLI e CALDART, 2002) encontramos descritos raça e etnia, apenas uma vez cada, como podemos ver a seguir:

"Defendemos um projeto de educação integral, preocupado também com as questões de gênero, de raça, de respeito às diferentes culturas [...]"

"[...] há ainda as diferenças de gênero, de etnia, de religião, de geração; são diferentes jeitos de produzir e de viver; diferentes modos de olhar o mundo, de conhecer a realidade e de resolver os problemas; diferentes jeitos de fazer a própria resistência no campo; diferentes lutas." (p21)

Contrariando os sentidos veiculados no Caderno 03, pontuamos a preocupação da Educação do Campo com as questões raciais e as diferenças étnicas, reconhecendo as diferenças de ser e existir como processos potentes para a unificação da luta e resistência no campesinato brasileiro. 
Assim, o texto aponta como é fundamental trazer o conceito de etnia e raça na Educação do Campo, e fortalecer o pertencimento étnico de sujeitos negros, pois essa é uma estratégia para questionar e descontruir representações étnico-raciais dominantes e racistas, para consolidar representações étnico-raciais alternativas (ZUBARAN e SILVA, 2012). Desta forma, a identificação étnica para a construção do país é essencial para a superação do racismo e desigualdade racial, e no desenvolvimento de uma educação voltada a diversidade e heterogeneidade do campo, para construção de uma identidade do campo que contemple os aspectos de raça, etnia, religião, gênero, entre outras dimensões dos sujeitos.

O Caderno 05 (MOLINA e JESUS, 2005) contemplou apenar o descrito étnicos, uma única vez:

“[...] a educação se realiza por organizações curriculares que trazem como conteúdos formativos as questões que sempre foram colocadas de fora dos conhecimentos escolares, tais como gênero, problemas ambientais, democracia, justiça social e paz, conflitos étnicos, necessidades especiais $[\ldots] "(p 72)$

Ao realizar essa reflexão, as autoras que constroem esse fragmento colocam a Educação do Campo enquanto espaço transversal, que dialoga com as necessidades e anseios do povo do campo em pautar questões que não se introduzem em modelos rígidos de educação hegemônica. Infelizmente, a questão étnica aparece apenas uma vez nesse caderno, o que é alarmante já que esse caderno tem como tema Contribuições para a construção de um Projeto de Educação do Campo. Assim, isso demonstra a ausência da discussão étnico-racial ao se pensar a construção desse projeto.

O Caderno 07 (SANTOS, 2008), que foi o último da Coleção Por uma Educação do Campo se destaca, pois achamos nele os descritores etnia, raça, racial, negra, negro, étnica. Isso demonstra certo desenvolvimento dessa pauta, mesmo que ainda pequeno, mas a de se inferir que esses conceitos ou palavras perpassaram os debates para a construção do documento.

"Temos que defender o direito à educação como direito universal, mas como direito concreto, [...]; seus sujeitos têm trajetórias humanas, de classe, de gênero, de etnia, de raça, em que vão se construindo como mulheres, indigenas, negros e negras, como trabalhadores, produtores do campo... Os movimentos sociais nomeiam os sujeitos dos direitos. (Citação de Arroyo, s/d, p. 28).

"[...] independem [...] de sermos brancos ou negros; não importa a questão racial, de classe, de sexo: o fato de sermos pessoa humana nos faz portadores desses direitos" (p. 23).

"Possibilidade de ampliar a discussão sobre gênero, questões étnicas e raciais nos currículos" (se refere aos avanços e aprendizagens possibilitadas pela Educação do Campo e PRONERA, para os sujeitos do campo)" (p.102). 
A citação de Arroyo no Caderno 07 desenvolve-se diversas perspectivas, pois o autor pauta a importância de se defender o direito compreendendo as trajetórias humanas de etnia e raça, na reafirmação desses como sujeitos de direitos no segundo trecho. Além disso, o texto demarca que a história que vem se construindo na Educação do Campo (através de suas práticas e vínculos com o PRONERA) possibilitou a discussão das relações étnico-raciais nos currículos. Assim, essas compreensões pontuam a importância da valorização da identidade étnico-racial do povo negro no Brasil, colocando a Educação do Campo como espaço capaz e que tem desenvolvido isso na construção de práticas educativas que "propiciem a valorização das múltiplas identidades que integram a identidade do povo brasileiro [do campo], por meio de um currículo que leve o aluno a conhecer suas origens e a se reconhecer como brasileiro" (MOURA, p. 69, 2005). Assim, o desafio da Educação do Campo se coloca em "reconhecer e valorizar as diferenças culturais, os diversos saberes e práticas, e a afirmar sua relação com o direito à educação de todos" (CANDAU, 2012, p.247).

Nota-se que há alguns fragmentos que discorrem sobre a Educação do Campo e as relações étnico-raciais na Coleção Por uma Educação do Campo, que é uma das grandes referências para se compreender o Movimento de Educação do Campo. Porém, são consideravelmente insuficientes e superficiais, pois em momento nenhum pontuam as questões com o mínimo de profundida nas relações étnico-raciais e a importância da educação do campo trata essa temática de maneira responsável e evidente. Assim, percebe-se que a Educação do Campo se centraliza na questão de classe, sempre pontuando os aspectos da classe trabalhadora do campo e a importância de uma Educação do Campo libertadora para essa classe. Porém, as questões que envolvem a relações étnico-raciais dessa classe trabalhadora, e que também estrutura a exclusão dos negros trabalhares do campo ainda ficam à margem. Não queremos dizer assim que a relações de classe não sejam fundamentais, pois são, mas as étnico-raciais são inerentes a essas relações socioeconômicas. Mais para frente discutiremos mais sobre isso.

$\mathrm{Na}$ Base de dados SciELO não encontramos nenhum artigo, já no Google achamos os artigo intitulado Educação no Campo e as Questões Étnico-Raciais: Um Desafio No Cotidiano Escolar, das autores Clara Suzane Silva Gomes, Danielle Lima Silva e Ildema Gomes Aragão, publicado em 2015 nos anais do Encontro Internacional de Formação de Professores e Fórum Permanente de Inovação Educacional. O texto é uma pesquisa de 
levantamento bibliográfico e de campo, em uma escola do campo, que teve como objetivo analisar e descobrir concepções étnica-raciais de alunos, a partir da observação e entrevistas. Os Autores afirmam que a partir dos resultados notaram a “[...] introjeção de estereótipos negativos em relação aos alunos negros, a não identificação com seu grupo e a fragilidades na sua própria identidade. [...]devemos nutrir ações que promovam a educação do/no campo, a partir, também, de um olhar direcionado às questões étnicoraciais" (GOMES, SILVA e ARAGÃO, 2015).

Desta forma, o estudo afirma como as escolas do campo vem reproduzindo lógicas de racismo e desigualdade, que é fruto da educação colonial e eurocêntrica, e aponta a necessidade de se realizar essa discussão de uma maneira mais profunda no contexto da educação do campo formal, para descontruir essa escola do campo que legitima o racismo, a inferiorização e impossibilidade das construções de uma identidade negra no campo. Assim, a Educação do Campo tem esse "desafio de como inventar as estratégias educativas e pedagógicas de combate ao racismo" (MUNANGA, 2005, p.18).

No Banco de Teses e Dissertações achamos uma dissertação que envolve a temática, da autora Leila de Lima Magalhães, intitulada $O$ campo tem cor?: presença/ausência do negro no currículo da educação do campo no Pará, do ano de 2009, na Universidade Federal do Pará. A dissertação teve como objetivo verificar as propostas de inclusão das relações étnico-raciais, com base na Lei 10639/03, nas propostas do Fórum Paraense de Educação do Campo (FPEC). A autora concluiu que apesar do FPEC articular sobre a questão das políticas públicas de educação do campo no Pará, a reflexão sobre a importância da diversidade no campo ainda é limitada, pois os debates que diz respeito sobre as relações étnico-raciais pautadas na Lei 10369/03 ainda era ausente no FPEC. A presença do tema consta nos documentos, mas não se efetiva nos debates colocados no FPEC. Além disso, a autora aponta que as propostas que existem são justificadas pelo fato do reconhecimento da população quilombola enquanto constituintes do campo. Porém, "população quilombola é vista desvinculada da luta do Movimento Negro, da diáspora africana, da população negra que está no meio rural e no espaço urbano como um todo" (MAGALHÃES, 2009, p.120). Assim, há a ausência de debates mais amplo, onde a educação do campo admita que as relações étnico-raciais é importante pelo fato do negro e negra estar compondo o campo como um todo, nos diversos espaços. Nesse sentido a autora afirma que a diversidade no campo 
[...] não se fundamenta apenas na categoria classe social. Os sujeitos do campo não são diversos pelo fato de serem pobres, ribeirinhos, extrativistas etc. Os sujeitos do campo possuem cor/raça. Num país que se organizou sob a égide do racismo este fato não é trivial. Ao contrário, esse fato tem sido fundamental para a elaboração das relações cotidianas (MAGALHÃES, 2009, p. 120).

\section{Qual a importância da Educação do Campo olhar para a relações étnico-raciais para fortalecer o Campesinato Negro?}

Buscamos pensar a Educação do Campo enquanto lugar possível para uma educação intercultural, que consiga pautar as diferenças entre os sujeitos, a diversidade, e compreender a importância do seu papel no processo de construção de identidade e afirmação cultural. Pois a Educação do Campo se coloca enquanto movimento que realiza a "crítica da educação em uma realidade historicamente determinada ela afirma e luta por uma concepção de educação (e de campo)" (CALDART, 2009, p.40). Assim, se coloca enquanto espaço potente para realização de uma educação emancipadora em diversos sentidos, em busca romper uma educação hegemonia e reprodução de desigualdade.

Desta maneira, olhando para o campesinato negro, pontuamos a importância da Educação do Campo na construção não somente da identidade camponesa, mas também da identidade negra. Nesse sentido, buscamos conceber uma Educação do Campo que assuma "[...] as diferenças como constitutivas da democracia e sejam capazes de construir relações novas, verdadeiramente igualitárias entre os diferentes grupos socioculturais, o que supõe empoderar aqueles que foram historicamente inferiorizados" (CADAU, 2012, p.244). Assim, admitir os diferentes sujeitos e identidade que compõem o campo, os sujeitos do campo que são negros, é fundamental para a consolidação de uma educação libertadora, pautada na igualdade e levando em conta as especificidades e as diferenças, principalmente para olhar para um grupo duplamente subalternizado que é o campesino negro, para assim lançar mão de ações de empoderamento e conscientização.

Desta forma, reconhecer que o campo possui raça e etnia e como essa questão se dá nas relações cotidianas, tendo em vista o racismo e a desigualdade racial, é essencial a Educação do Campo assumir esse lugar, tendo em vista que o negro ocupa o campo em sua heterogeneidade. Pois, para a Educação do Campo "afirmar a população negra precisa enfrentar o desafio de olhar os sujeitos do campo [...] na diferença de sua cor/raça [...]. E incluir as peculiaridades que envolvem essas diferenças em suas propostas e reivindicações" (MAGALHÃES, 2009, p.121). 
Sem se esquecer de que a Educação do Campo é uma luta dos Movimentos Sociais do Campo, que tem como constituição também o Movimento Negro, assim, esses diálogos e trocas de experiências e unificação dos movimentos é essencial para a interculturalidade e para a compressão de uma identidade negra e camponesa. Esse exercício possibilita olharmos e admitirmos que a construção de lugar (campo) e desses sujeitos negro, é rodeando por complexidade, e por identidade que passaram por ações que buscaram sua fragmentação e inferiorização, que destroem a autoestima dos sujeitos negros (GOMES, 2003) e camponeses, que impossibilita o reconhecimento do seu lugar de sujeitos de direito que valoriza e pertence a uma cultura camponesa e negra, pois esse campo tem cor. A Educação do Campo enquanto movimento sócio-político cultural é lugar essencial para esses reconhecimentos e para pensar estratégias para potencializar essas identidades, fortalecer o campesinato negro enquanto sujeitos potentes e que carregam a cultura negra e camponesa em suas expressões, a cor da sua pele, cabelos, modos de organização, expressão cultural, ancestralidade, para assim reabilitar de seus valores e sua identidade.

Essa perspectiva é afirmada por Magalhães (2010) ao colocara que

[...] a Educação do Campo como instrumento para reafirmar os sujeitos negros do campo deve se comprometer com a reeducação para as relações étnicoraciais, como forma de combater o racismo e a desigualdade racial, que excluem a população negra de ser reconhecida como sujeito de direito (s/p).

Dentro desse percurso a educação do campo olha para o sujeito negro do campo para superar lógicas de inferiorização, os afirmando enquanto sujeitos de direito. Assim, a Educação do Campo vai além de afirmar o camponês (de forma genérica) como sujeito de direito e buscar sua valorização cultural, histórica, social e política, mas vai também compreender a diversidade étnico-racial do campo, pois ser negro ou não negro no campo faz diferença. Nesse sentido, ser negro e camponês marca uma dupla marginalização histórica e contemporânea em âmbito política, socioeconômica e cultural, tendo a Educação do Campo o potencial e a necessidade de realizar essas reflexões e admitir as diferenças para a construção de identidade a partir de suas especificidades (pois o campo é heterogêneo). Essa questão não busca fragmentar os coletivos, grupos ou comunidades, pelo contrário, busca-se reconhecer suas diferenças, mas também suas inter-relações para a consolidação da sociedade brasileira. Desta forma, trata-se de olhar para as especificidades do campesinato negro e para a valorização de suas existências como sujeitos de direitos, e assim para unificação da luta dos oprimidos contra as injustiças sociais que marcam os 
diversos grupos oprimidos (mulheres, índios, transexuais, homossexuais, sujeitos da periferia urbana). Assim, o movimento é de conscientizar as diversas opressões, para assim empoderar os sujeitos para a ação coletiva para a busca de uma sociedade mais justa.

Sobre as questões que envolvem o campesinato negro, Gusmão (1990) aponta para as especificidades de ser e existir no campo enquanto negro e camponês. A autora afirma que o campesinato negro apesar de se caracterizar por vivências comuns a qualquer grupo do campo (processo de produção - agricultura camponesa familiar, organização familiar e comunitária, cultura, crenças, modos de vida em geral) está articulado com a produção histórica, ancestral e cultural que marca a existência do ser negro. Assim, aciona uma existência vinculada com essas duas dinâmicas, e que se coloca a partir dos modos de existência camponesa e os modos de existência do negro (etnicamente e racialmente diferente), que marcam e que estão em pleno movimento na luta pela terra e pelo acesso ao conhecimento para o campo.

Nesse sentido, reafirmamos a busca por uma Educação do Campo que supere as concepções de ser negro e camponês que inferiorizaram e inferiorizam esses segmentos, e buscar estratégias para se pensar na potencialização da identidade negra e camponesa, entendendo seus diálogos e suas especificidades, tendo em vista que a construção dessas identidades perpassam dimensões sociais, culturais, políticas e históricas, marcadas pelo conflito e pela reprodução. Para isso "é preciso assumir o compromisso pedagógico e social de superar o racismo [e o urbanocentrismo], entendendo-o à luz da história e da realidade social [camponesa] e racial do nosso país" (GOMES, 2002, p.05), e assim "que propiciem a valorização das múltiplas identidades que integram a identidade do povo brasileiro" (MOURA, 2005, p.69).

Sendo assim, pontua-se que a Educação do Campo deve olhar de maneira mais intensa para as relações étnico-raciais, pois existe um campesinato negro, que deve ser pautado de maneira mais especifica, sobre seus processos históricos e culturais não só como camponeses, mas como sujeitos negros, assim, precisa-se de uma Educação do Campo que fortaleça questões identitárias enquanto camponês e negro, que tenha como prática superar os estereótipos, para o sujeito negro e camponês desativar os aspectos incorporados como negativos sobre si (produzida pelas práticas sociais). E que não reproduzam lógicas de racismo e desigualdade racial de forma naturalizada, para contribuir para o empoderamento do campesinato negro enquanto pertencente a uma 
cultura e história negra e camponesa, colocando-se enquanto sujeito de direito e agente de transformação de valores arbitrários, eurocêntrico, urbanocêntricos, brancos e hegemônicos.

A educação das relações étnico-raciais tem como objetivo o desenvolvimento de movimentos de formação humana, de mulheres e homens, pautadas nos direitos sociais, políticos, culturais, de ser, reexistir e viver a partir de percursos de pertenciamento étnicoraciais possíveis e saudáveis (SILVA, 2007), o que é também missão da educação do campo.

\begin{abstract}
Em outras palavras, persegue o objetivo precípuo de desencadear aprendizagens e ensinos em que se efetive participação no espaço público. Isto é, em que se formem homens e mulheres comprometidos com e na discussão de questões de interesse geral, sendo capazes de reconhecer e valorizar visões de mundo, experiências históricas, contribuições dos diferentes povos que têm formado a nação, bem como de negociar prioridades, coordenando diferentes interesses, propósitos, desejos, além de propor políticas que contemplem efetivamente a todos (SILVA, 2007, p. 490).
\end{abstract}

Assim, aqui pontuamos a essencialidade de se desenvolver o reconhecimento e valorização nas relações étnico-raciais via Educação do Campo, pontuando centralmente a importância disso quando se diz respeito ao negro e ao camponês no Brasil e o racismo e desigualdade racial e social que ainda marca sua existência. Na busca de afirmar a identidade negra e camponesa, sua historicidade e modos de existir, sendo um exercício para a educação antirracista e intercultural, que contemple as necessidades do negro, sem se esquecer da importância disso se efetivar dentro das políticas públicas.

\title{
É possível construir uma Educação do Campo libertadora para os sujeitos negros e não negros sem pautar os tencionamentos das relações étnico-raciais?
}

Essa resposta podemos afirmar de maneira sólida, não, pois entendemos que olhar, pautar, discutir (seja no âmbito teórico-prático, seja no âmbito dos movimentos sociais, políticos e culturais, ou nas questões da política pública da Educação do Campo) as relações étnico-raciais são fundamentais para a realização de uma Educação do Campo libertadora. Isso se justifica por primeiro as estruturas de opressões econômicas e sociais não perpassam apenas a estrutura de classe, mas as relações étnico-raciais, assim, para destruí-las é necessário fortalecer uma rede interseccional contra opressões. Pois, concebemos que "De forma alguma as relações culturais e sociais entre negros e brancos em nosso país podem ser pensadas como harmoniosas, democráticas e diluídas nas questões socioeconômicas" (GOMES, 2003, p.77). E segundo a educação de modo geral, 
deve estar pautada na superação de qualquer reprodução de desigualdade, seja ela de classe, etnia, raça, gênero ou orientação sexual, para superar preconceitos introjetados e que sustentam as estruturas que oprimem as minorias do campo.

Caldart (2009) afirma que a Educação do Campo "[...] nasce da 'experiência de classe' de camponeses organizados em movimentos sociais e envolve diferentes sujeitos, às vezes com diferentes posições de classe" (p.38). Mas afirmamos aqui mais uma vez que essa classe, que constituem a heterogeneidade do campo brasileiro, possui uma raça e etnia que determina suas relações com o mundo, e que perpassa uma história e conjuntura de racismo e desigualdade racial (MAGALHÃES, 2009). Assim, se a Educação do Campo instaura um projeto societário anticapitalista (CALDART, 2008), é necessário entender que a estrutura do capitalismo está vinculada com outros padrões de poder, desta forma a educação do campo deve buscar também por práticas e perspectivas decoloniais, antirracista, antissexistas, anti-machistas, anti-transfobicas, anti-homofobicas, ou seja, antiopressões, para que assim seja possível romper com a estrutura capitalista.

O desconhecimento e o abafamento das vivências, formas de ser, pensar e realizar dos povos negros brasileiros e africanos, realizados pela colonialidade, fez com que os sujeitos configurassem uma sociedade monocultura, e assim, uma educação nesse mesmo sentido, eurocêntrica e colonializadora. "Isto nos tornam incapazes de corrigir a ilusão da democracia racial, de vencer determinações de sistema mundo centrado em cosmovisão representativa de uma única raiz étnico-racial" (SILVA, 2007, p.501). Assim nos impede a olhar para as experiências e saberes produzidos pelos povos negros, além disso, torna incapaz olhar para os sujeitos da classe trabalhadora, mulheres, indígenas, idosos, homossexuais. Desta forma, existe o apagamento de diversos sujeitos nos processos educativos, sendo latente a necessidade de rompe com essa lógica. Afirmando mais uma vez a necessidade de se olhar para os múltiplos processos de opressão, que não perpassam apenas a lógica de classe.

Silva (1987) ao se debruar sobre as questões de trabalhadores negros do campo, indaga sobre os processos que perpassam suas vivências, suas compressões e sentidos de mundo construídos nas relações sociais desses sujeitos. A autora afirma que essas questões e produção de sentidos desses sujeitos perpassam o contexto econômico e político que se organiza a sociedade e os tencionam enquanto classe trabalhadora, mas também, por serem negros, não perpassa somente a questão econômica, mas os aspectos 
raciais, que é marcada pelas relações inter-raciais ou étnico-raciais. Assim, afirma mais uma vez a necessidade de olhar para a classe trabalhadora e suas diferenças raciais, pois isso estrutura suas relações com o mundo.

As poucas discussões sobre o negro camponês na Educação do Campo é resultado do racismo (MAGALHÃES, 2010). Assim, olhar para as relações étnico-raciais é potencializar a educação do campo enquanto possibilidade alternativa de educação contra-hegemônica, para que ela não caia nos mesmos padrões de reprodução e silenciamento do racismo e das desigualdades raciais do modelo colonizador, urbanocêntrico, eurocêntrico e hegemônico de educação que legitima práticas de preconceitos, nas relações sociais, nos livros didáticos, nas formas de lidar com os estudantes, nas práticas de exclusão e inferiorização (MUNANGA, 2005).

\section{CONCLUSÕES}

Fica evidente a necessidade da Educação do Campo não olhar para o campo brasileiro somente através das relações de classe, mas também das relações étnico-raciais, pois esses sujeitos possuem uma cor de pele, textura de cabelo, traços fenótipos que marcam suas relações sociais e cotidianas. $\mathrm{O}$ que afirma as questões que foram colocadas na análise da Coleção Por uma Educação do Campo, a superficialidade da discussão sobre o negro camponês e a negra camponesa, que não dá conta de fazer tencionamentos diretos para propor práticas antirracista, problematizando a desigualdade racial que também perpassa o campo e vida da classe trabalhadora.

Além disso, pensar e discutir as questões que envolvem o campesinato negro é pauta fundamental para se construir estratégias para colocar em prática a Lei 10.639/03, na Educação Básica do Campo, e se pensar a formação dos Educadores do Campo, a partir das Licenciaturas em Educação do Campo. Nesse sentido, é pertinente dialogar essa lei com as experiências do negro em toda a sociedade, no processo de valorização de sua existência e, além disso, olhar par a atuação do negro nesse território camponês, compreendendo o campo como um espaço com diversos sujeitos negros que contribuem para a sua construção social, produtiva, cultural e educativa do campo. A Lei almeja ampliar o conhecimento histórico e cultural "silenciados pelo projeto de educação eurocêntrica e hegemônica construído pela elite dominante branca. Projeto este que teve o intuito de negar a negritude e a identidade negra brasileira" (MAGALHÃES, 2010, s/p). 
Assim, a Lei vai de encontro com os próprios princípios da Educação do Campo enquanto projeto contra-hegemônico de educação para o campo.

Desta maneira, tratar as questões das relações étnico-raciais e as desigualdades raciais são fundamentais para consolidar uma Educação do Campo potente para realizar movimentos contra-hegemônicos nas relações de desigualdade, e para consolidar uma Educação Libertadora, intercultural, transformadora das relações de opressão e decolonial, almejando um projeto societário popular e revolucionário para sujeitos negros e não negros.

\section{Notas}

${ }^{1}$ Entendendo esses conceitos dentro da compreensão Freireana.

${ }^{2}$ A Identidade é compreendida aqui "como uma construção social, histórica, cultural e plural. Implica a construção do olhar de um grupo étnico/racial ou de sujeitos que pertencem a um mesmo grupo étnico/racial sobre si mesmos, a partir da relação com o outro" (GOMES, 2003, p.171).

\section{REFERÊNCIAS}

ARROYO, Miguel Gonzalez e FERNANDES, Bernardo Mançano (Orgs). A educação Básica e o movimento social do campo. Coleção Por Uma Educação Básica do Campo - Caderno 2. Luziânia $\square$ GO, 1998, 67p.

BENJAMIN, César e CALDART, Roseli Salete (Orgs). Projeto Popular e escolas do campo. Coleção Por Uma Educação Básica do Campo - Caderno 3. Brasília: Fundação Universidade de Brasília, 2000, 63p.

CALDART, Roseli Salete. Sobre educação do campo. In: SANTOS, Clarice Aparecida dos (Org.). Educação do campo: campo - políticas públicas - educação. (NEAD Especial: 10). Brasília: INCRA; MDA, 2008. p. 67-97.

CALDART, R. S. Educação do campo: notas para uma análise de percurso. Trab. Educ. Saúde, Rio de Janeiro, v. 7 n. 1, p. 35-64,mar./jun.2009.

CALDART, R. S. Educação do Campo. In: CALDART, Roseli et al. (org.). Dicionário da Educação do Campo. Rio de Janeiro: Escola Politécnica de Saúde Joaquim Venâncio, Expressão Popular, 2012, p. 257-265.

CANDAU, Vera Maria Ferrão. Diferenças culturais, interculturalidade e educação em direitos humanos. Educ. Soc., Campinas, v. 33, n. 118, p. 235-250, jan.-mar. 2012.

FANON, Frantz. Em defesa da revolução Africana. Lisboa. Livraria Sá da Costa. 1969.

GONZALEZ, Lélia; HASENBALG, Carlos. Lugar de negro. - Rio de Janeiro: Marco Zero, 1982. 
GOMES, Clara Suzane Silva, SILVA, Danielle Lima e ARAGÃO, Ildema Gomes. Educação no campo e as questões étnico-raciais: um desafio no cotidiano escolar. In.: Anais do VIII Encontro Internacional de Formação de Professores, IX Fórum Permanente de Inovação Educacional - Aracaju: Unit, 2015. 2015

GOMES, Nilma Lino. Educação e identidade negra. Revista Aletria: alteridades em questão, Belo Horizonte, POSLIT/CEL, Faculdade de Letras da UFMG, v.06, n.09, dez/2002, p. 38-47.

GOMES, Nilma Lino. Cultura negra e educação. Revista Brasileira de Educação, $\mathrm{n}^{\circ} 23$ Maio/Jun/Jul/Ago 2003.

GOMES, Nilma Lino. Alguns termos e conceitos presentes no debate sobre relações raciais no Brasil: uma breve discussão. In.: Educação anti-racista: caminhos abertos pela Lei Federal $n^{\circ}$ 10.639/03 / Secretaria de Educação Continuada, Alfabetização e Diversidade. - Brasília: Ministério da Educação, Secretaria de Educação Continuada, Alfabetização e Diversidade, 2005.

GOMES, Nilma Lino. Relações étnico-raciais, educação e descolonização dos currículos. Currículo sem Fronteiras, v.12, n.1, pp. 98-109, Jan/Abr 2012.

GUSMÃO, Neusa Maria Mendes de. A questão política das chamadas "terras de preto". TEXTOS E DEBATES. Publicação do Núcleo de Estudos sobre Identidade e Relações Interétnicas- UFSC, ano I, n• 2, 1990.

KOLLING, Edgard Jorge; CERIOLI, Paulo Ricardo; CALDART, Roseli Salete (Orgs). Educação do Campo: Identidade e Políticas Públicas. Coleção Por uma Educação do Campo - Caderno 4, Brasilia-DF, 2002, 92p.

MAGALHÃES, Leila de Lima. O Campo tem cor?: presença/ausência do negro no currículo da educação do campo no Pará. Dissertação (Mestrado em Educação). Universidade Federal do Pará, Instituto de Ciências da Educação, Programa de PósGraduação em Educação, Belém, 2009.

MAGALHÃES, Leila de Lima. A Lei no 10.639/03 na Educação do Campo: garantindo direito às populações do campo. In.: ANTUNES- ROCHA, Maria Isabel e HAGE, Salomão Mufarrej. Escola de direito: reinventando a escola multisseriada. - Belo Horizonte: Autêntica Editora, 2010. - (Coleção Caminhos da Educação do Campo; 2). Disponível em: $<$ https://books.google.com.br/books?id=jy6IAwAAQBAJ\&printsec=frontcover\&hl=ptBR $\&$ source $=\mathrm{gbs} \_g e \_s u m m a r y \_r \& c a d=0 \# \mathrm{v}=$ onepage $\& \mathrm{q} \& \mathrm{f}=$ false $>$ Acesso em: 01 de dezembro de 2016.

MOLINA, Mônica Castagna; JESUS, Sônia Meire Santos Azevedo de (Orgs). Contribuições para a Construção de um Projeto de Educação do Campo. Coleção Por Uma Educação do Campo - Caderno 5. Brasilia-- $\square$ DF, 2005, 75p.

MOLINA, M. C. Educação do Campo e Pesquisa: questões para reflexão. Brasília: Ministério do Desenvolvimento Agrário, 2006. 
MOURA, Gloria. O Direito à Diferença. In.: MUNANGA, Kabengele (Org.). Superando o Racismo na escola. Brasília: Ministério da Educação, Secretaria de Educação Continuada, Alfabetização e Diversidade, 2005

MUNANGA, Kabengele. Apresentação. In.: MUNANGA, Kabengele (Org.). Superando o Racismo na escola. Brasília: Ministério da Educação, Secretaria de Educação Continuada, Alfabetização e Diversidade, 2005.

MUNANGA, Kabengele. Negritude: usos e sentidos; Coleção Cultura Negra e Identidades. Belo Horizonte: Autêntica, 2009.

MUNANGA, Kabengele e GOMES, Nilma Lino. O negro no Brasil de hoje. 2. ed.- São Paulo: Global, 2016.

NASCIMENTO, Abdias. do. O genocídio do negro brasileiro: processo de um racismo mascarado. Rio de Janeiro: Editora Paz e Terra, 1978.

SANTOS, Clarice Aparecida dos (Org). Educação do Campo: campo - políticas públicas - educação. Coleção Por uma Educação do Campo - Caderno 7. Brasília-DF: INCRA; MDA, 2008, 117p.

SILVA, Petronilha Beatriz Goncalves e. Educação e identidade dos negros trabalhadores rurais do limoeiro. Tese (Doutorado em Educação) UFRGS, 1987.

SILVA, Petronilha Beatriz Gonçalves e; BARBOSA, Lucia Maria de Assunção. O Pensamento Negro em Educação no Brasil. São Carlos: UFSCar, 1997.

SILVA, Petronilha Beatriz Gonçalves e. Pode a educação prevenir contra o racismo e a intolerância? In: Seminários Regionias preparatórios para a Conferência Mundial contra o Racismo, Discriminação Racial, Xenofobia e Intolerância Correlata. 2001. Disponpivel em: < http://conexoesufrb.blogspot.com.br/2009/06/texto-05-podeeducacao-prevenir-contra.html>. Acesso em 01 de dezembro de 2016.

SILVA, Petronilha Beatriz Gonçalves e. Aprender, ensinar e relações étnico-raciais no Brasil. Educação. Porto Alegre/RS, ano XXX, n. 3 (63), p. 489-506, set./dez. 2007.

WALSH, Catherine. Interculturalidade Crítica e Pedagogia Decolonial: in-surgir, re-existir e re-viver. In. CANDAU, Vera Maria (Org.). Educação intercultural na América Latina: entre concepções, tensões e propostas. Rio de Janeiro: 7 Letras, 2009. p. 12-43.

ZUBARAN, Maria Angélica e SILVA, Petronilha Beatriz Gonçalves e. Interlocuções sobre estudos afro-brasileiros: Pertencimento étnico-racial, memórias negras e patrimônio cultural afro-brasileiro. Currículo sem Fronteiras, v.12, n.1, pp. 130-140, Jan/Abr 2012.

Recebido em 20/03/2017.

Aceito para publicação em 12/03/2018. 